\title{
Modern pedagogical technologies in the system of additional professional education
}

\author{
A.N. Ilyasova ${ }^{1 *}$, J.L. Grebennikov ${ }^{2}$, and E.A. Ramazanova ${ }^{3}$ \\ ${ }^{1}$ V.I. Vernadsky Crimean Federal University, Simferopol, Russia \\ 2 State Higher Education Institution of the Moscow Region Moscow Region State University, \\ Mytishchi, Russia \\ ${ }^{3}$ State Budget Educational Institution of Higher Education of the Republic of Crimea Crimean \\ Engineering and Pedagogical University the name of Fevzi Yakubov, Simferopol, Russia
}

\begin{abstract}
The text of this article reflects the results of theoretical and practical research in the field of equipping the system of additional professional education with the means of modern pedagogical technologies that affect the quality of professional training of future specialists. The most relevant pedagogical technologies are considered separately, and their effectiveness or ineffectiveness is confirmed by means of online questionnaires. Besides, a significant segment of the study is devoted to reviewing and comparing the experience of predecessors in this matter. The role of personality -oriented and competence-based approaches in the system of additional vocational education is revealed and actualized, their individual elements, especially significant for research, are singled out. A special place in the structure of the study is occupied by the chosen key method - online questionnaire, which is based on data provided by more than 150 teachers of the systems of both higher professional and additional professional education. All of them are not geographically tied to one place, in connection with which one can judge the objectivity of their opinions, as well as the vast geography of the dissemination of the research results. This method is one of the most effective and promising methods of scientific analytical and reflective research.
\end{abstract}

\section{A problem statement}

The sphere of professional education is undergoing a certain spectrum of changes, in accordance with which a certain range of problems and crisis points arise. The abundance of means and mechanisms of influence on the optimization of the process of professional training of students in conditions of higher professional education is graded by the lack of the same funds in the system of additional professional education. Such an educational system today has all the necessary potential to displace the official educational systems and become the dominant one. This state of affairs is dictated by the new economy, within which the tendencies of obtaining additional professional education along with the traditional one are developing [11].

\footnotetext{
*Corresponding author: ipcs-profped@yandex.ru
} 
Thus, a number of issues and problems are formed related to the provision of such a system with modern pedagogical and other (information and communication, educational, digital, etc.) technologies. The introduction of such technologies will allow extensive experimental platforms for additional professional education to form their own concept of development and access to a higher state level. Accordingly, it would be fair to designate the above thesis as a key research problem, on the basis of which a system of problematization and goal setting is formed.

\subsection{The objective of the work}

This problem was reflected in the works of a lot of native and foreign authors. But, despite this, a fairly small range of problems was solved (even in the form of a theoretical justification or hypothesis). This allows us to build our own research in such a way that, based on theoretical material, to present new practical data that can supplement the pedagogical base. The theoretical basis of the study was the work of such domestic and foreign authors as G.S. Altshuller, B.P. Baidenko, V.P. Bespalko, I.P. Volkov, A.A. Getmanskaya, T.E. Zlygosteva, V.A. Cavera, M.V. Klarin, V. Knyaginin, N. Trunova, I.A. Kolesnikova, I.Ya. Lerner, T.M. Mikhailenko, M.Yu. Oleshkov, B.A. Sazonov, G.K. Selevko, T.B. Feiling, A.S. Chernov, M.A. Choshanov, V.D. Shadrikov, I.S. Yakimanskaya and others.

The works of these scientists formed the basis of this study and became a significant stage in the process of comprehending the above-described problems. They made it possible to replenish the basis with the necessary theoretical and practical data, which allow us to actualize the need to solve the described problem and come to a single pedagogical consensus.

\section{Materials and the results of the research}

To realize the most effective conceptual study, we have identified a range of tasks leading to the formation of a global aim of all the work. These tasks include:

- the identifying of the specifics of modern pedagogical technologies, as well as the specifics of the system of additional professional education, within which they are being implemented;

- the identification of problems and potential for the introduction of such technologies in the process of additional professional training of specialists of different directions and degrees of knowledge;

- the conducting of an analytical study (in the form of a questionnaire) underlying the disclosure of the topic;

- the research of the experience of leading teachers and other scientists involved in the development of this topic;

- the determination of the most effective and ineffective modern pedagogical technologies used in the system of additional professional education.

Based on the above-mentioned tasks, by the purpose of this study we mean a complete study of the described problems, as well as the identification of patterns and contradictions between the options for using modern pedagogical technologies in the system of additional vocational education.

The essence of a modern institution of additional professional education consists in the organization and management of its educational processes [3]. They are built on the basis of a compilation of a wide variety of student activities, in connection with which the possibility of free choice of the individual tempo for each student, the depth and fullness of the educational material is generated. Besides, additional professional education implies the 
presence of representatives of different agesin one social group. This allows various specialists to exchange experience and turn to the study of new phenomena and situations for them [10].

For many years many researchers have singled out all kinds of tools as fast, free and objective methods for optimizing the system of additional higher education, but modern pedagogical technologies considered in this study turned out to be the most effective [9].Moreover, it is important to remember that the success of attracting such technologies to the system of organizational and administrative measures depends not so much on the personal and professional abilities of the teacher in this area, but on the effectiveness of the use of a competently and timely chosen method, implemented at a specific stage of the training session.

Of course, let's pay tribute to the personality of the teacher, which also partially affects the result of the use of technologies. At any stage of the development of education, at any stage of obtaining professional competencies for each student, there remains one indisputable authority - a qualified teacher who knows his job and is capable of optimizing it. The most important personal quality for a teacher in this regard is independence [6]. Moreover, it should manifest itself not only in practical activity, but should affect the mental, analytical, and reflexive aspects of a specialist. In other words, the teacher must be a person who is able to withstand any problems, to own his own knowledge, skills, actions and emotions entirely, and also to pass this experience on to subsequent generations.

In modern pedagogical science, it is accepted to understand pedagogical technology as a kind of "a set of psychological and pedagogical attitudes that determine a special set and arrangement of forms, techniques, means, teaching methods, educational tools" [12]. In this regard it would be fair to note that such a set is a certain organizational and methodological tool used for the development of the pedagogical process.

M.Yu. Oleshkov, in accordance with this, believes that all pedagogical technologies have certain distinctive features, which are reflected in the following list:

- universality, consisting mainly of the independence of technology and its specifics of the information content of the disciplineor a number of disciplines being studied;

- reproducibility, which can be characterized as independence from external and internal factors - from the personal characteristics of teachers and students, etc.;

- replicability, directly related to the previous point - the reproducibility of the results;

-manageability of the educational process, based on the systematization and phasing of educational and pedagogical procedures, etc. $[12 ; 13 ; 15]$.

The researcher notes that any technique that does not possess at least one of the above elements can never become a technology. Thus, the special specificity of such technologies and their reflection in the modern educational process is emphasized. It is important to take this aspect into account in the formation and pedagogical development of such technologies, as well as with their especially active application in practice [14].

So, having dealt with the specifics and essence of modern pedagogical technologies that are actively being introduced into the system of additional professional education, we will focus on some especially significant technologies, as well as their features, which will be especially useful for us in the case of an analytical study. Many researchers note that the general professional qualifications of modern professionals are determined primarily by regular retraining, replenishment of already existing knowledge bases and continuous education (lifelong education, as this system is commonly called) $[2 ; 3 ; 5 ; 6 ; 7 ; 9 ; 10 ; 12$; $13 ; 15]$. Thus, it is possible to trace the aspects of updating the programs of additional vocational education, as key requirements for the developed production of supplying with the comprehensive training of future specialists.

Some researchers consider the programs of additional qualifications to be one of the leading forms of implementation of additional professional education, which are focused on 
optimizing the educational process, comparing of the abilities and capabilities of students, as well as on stimulating students to get professional education. As a rule, the capacity of such a program exceeds one thousand hours, which indicates the immeasurable potential and educational effectiveness of such education. At the same time, such an additional program allows students to carry out the parallel acquisition of professional competencies in accordance with various educational programs [17].

The method of parallelism is another distinctive striking feature of the system of additional vocational education, which largely influences the process of forming an effective learning trajectory and educational route [19]. Through it, a student can acquire two specialties at the same time, which allows expanding the student's opportunities in the field of his future professional activity. In addition, there are a number of goals pursued by students in the process of obtaining two specialties at the same time:

-the significant expansion and deepening of the professional capabilities of specialists in the field of their professional activities;

-the significant increase in professional mobility, competitiveness and relevance of a specialist in a developing labor market and socio-cultural space with its regular and spontaneous changes;

- the pedagogical and educational optimization of the structure of professional training of a graduate, aimed at carrying out activities in the conditions of the intellectual (or intellectual and creative) labor market;

- the efficient and up to date response of the educational system and educational organization to the formation and development of elements of the intellectual labor market;

- the significant increase in the quality of educational services, an increase in the efficiency of vocational education, etc. [15].

T.B. Feiling, in connection with the above-described, believes that the system of parallel additional professional education is focused primarily on educated, developed, wellperforming, mobile and motivated students who show a desire to expand their own intellectual capabilities [15].

In addition to the previously described parallel, there is modular training aimed at forming a fundamentally new approach to project activities in the field of education. This type of education is aimed not at the simple transferring or exchanging of data and materials, but at the formation of a clear structure of competence in the student, which will later form the basis of the professional and general culture of the individual.

The key goal of such education is considered to be the perfection of the level and the improvement of the quality of the process of teaching and upbringing through the local step-by-step nature of its construction. The modules of such a system act as some kind of flexible educational elements that structure the content of the theoretical mastering of disciplines, and also develop the dynamism and potential of this content. Because of this they do not have such a system as classical lectures and seminars, which cannot be swapped, because in this case something important will be missed. The modules are not so connected with each other, which allows you to get acquainted with the main aspects of each blockquickly and without disruption to the course, and then to choose the sequence of their studying.

As it can be seen from the above-mentioned, the system of additional professional education is quite many-sided and specific. It has a mass of complex and ambiguous structures and elements, which allows it to have a significant impact on the system of higher professional education as a whole. The experience of using parallel and modular training has shown that with the proper degree of teacher and student activity, it is possible to achieve even greater success than within the framework of the traditional system, which largely determines the potential for the spread and popularization of the system of additional education. At the same time the key task of a teacher of such education remains 
to motivate and encourage a student to act. It is important not so much to exchange information and to put it bit by bit into the student's head, but to create conditions that would be able to reveal the individual abilities of each student, generate a project for the development of creative, social and professional beginnings of a future specialist.

Based on the foregoing, let us turn our attention to the existing modern pedagogical technologies that provide the above-described effect from additional professional education. This is necessary to understand the essence of such technologies and the degree of their influence on the educational environment as a whole. To do this, we conducted a study to identify the most effective, in the opinion of teachers of additional education, modern pedagogical technologies. The survey was carried out among many teachers who are not geographically tied to one place. In other words, different teachers from different regions of the Russian Federation took part in the survey, which allowed us to make a fairly extensive sample and conduct a full study of the phenomenon of additional professional education. The results of the research can be found below, in the table under the number " 1 ".

Table 1. Evaluation of the effectiveness of modern pedagogical technologies (left column) in the system of additional professional education by practicing specialists in this field (the results are reflected in $\%$ in four columns).

\begin{tabular}{|l|c|c|c|c|}
\hline & $\begin{array}{l}\text { Fully } \\
\text { effective }\end{array}$ & $\begin{array}{l}\text { More effective } \\
\text { than in } \\
\text { effective }\end{array}$ & $\begin{array}{l}\text { More in } \\
\text { effective than } \\
\text { effective }\end{array}$ & $\begin{array}{l}\text { Completely } \\
\text { in effective }\end{array}$ \\
\hline Communication technology & 13,2 & 20,4 & $\mathbf{4 0 , 1}$ & 26,3 \\
\hline $\begin{array}{l}\text { Technology for solving } \\
\text { inventive problems }\end{array}$ & $\mathbf{3 5 , 5}$ & 30,4 & 23,5 & 10,6 \\
\hline $\begin{array}{l}\text { Programmed learning } \\
\text { technology }\end{array}$ & $\mathbf{4 0 , 1}$ & 35,2 & 19,5 & 5,2 \\
\hline Problem learning technology & $\mathbf{3 8 , 2}$ & 29,5 & 20,9 & 11,4 \\
\hline $\begin{array}{l}\text { Technology of pedagogical } \\
\text { cooperation }\end{array}$ & 28 & $\mathbf{4 4 , 2}$ & 11,6 & 16,2 \\
\hline $\begin{array}{l}\text { Adaptive learning } \\
\text { technologies }\end{array}$ & $\mathbf{4 1 , 9}$ & 28,3 & 7,1 & 6,5 \\
\hline $\begin{array}{l}\text { Individualized learning } \\
\text { technology }\end{array}$ & 21,9 & $\mathbf{3 9 , 8}$ & 15,7 & 22,6 \\
\hline
\end{tabular}

Based on the results reflected in the above table, the following technologies became the most effective, in the opinion of teachers of additional professional education:

- the technology of solving inventive problems (65.9\%) is often considered in scientific pedagogical literature as the pedagogy of creativity. It is a unified educational and methodological system, within which the elements of cognitive activity and segments of active methods of activating creative thinking are harmoniously combined. At the same time, the student solves creative problems arising in the process of his additional professional training, absolutely independently, which especially emphasizes the potential of this technology and its relevance [1;3];

- the technology of programmed learning $(75.3 \%)$ is based on the material and technical base of an educational institution or an academic discipline (in the case of a distance form of additional professional education) and assumes the rapid and intensive perception by a student of programmed educational material trough the using of this very base. The key specific characteristic here lies in the algorithmic nature of the presentation of educational material, as well as in a small amount of it, which allows the student to focus on every discussed aspect of the discipline or field of knowledge. The largest type of such technology today is considered to be the system of modular education, which we regarded in detail earlier [4]; 
- the technology of problem-based learning (67.7\%) has a special educational and breeding potential, since during the educational sessions a teacher or a tutor creates conditions for the development of a problem situation, or initially introduces a studentto a problem situation, the solution of which must be sought by the student independently. The teacher here acts as a "supervisor", trying not to interfere in the process of solving problem tasks by the student. Such activity allows to master knowledge and skills in a fairly intensive form, as well as to enhance the cognitive activity of the student significantly [17];

- the technology of pedagogical cooperation $(72.2 \%)$, which involves the provision of assistance by the teacher to the student, but only in the amount the former needs, since it is still focused on the independent mastering of the educational program. Here the teacher can give advice and tips, but not fulfil the task for the student;

- the technology of the adaptive learning system (70.2\%) consists in the fact that the teacher develops a special individual approach aimed at developing the individual abilities of the student, however, the training takes place within the framework of the educational institution and is somehow controlled by the leading teacher. It is important to mention that adaptive technology is based on an individual approach, which is reflected in all the existing modern pedagogical technologies, in connection with which it is called penetrating technology [19].

- the technology of individual training (personality-oriented technology) $(61.7 \%)$. We should note that this technology crosses the previous one and is also aimed at forming an individual educational route for each of the students, however, in this case, the student's independent control within the framework of the additional professional education system is implied. This is due to the fact that the student independently chooses an additional professional profile, in accordance with which he is responsible for his choice and learns to control his activities on his own [19].

The least effective was communication technology $(66.4 \%$ of respondents rated its effectiveness below average or very low), based on the experience of respondents. Perhaps this is due to different conditions for the implementation of this technology within the system of additional professional education.

\section{Conclusions}

In conclusion of this study, I would like to note the special potential of the system of additional professional education, which nowadays already manifests itself at a sufficiently high conceptual level and is a priority area for the development of modern pedagogy. Besides, it is precisely such an education that provides a lot of new opportunities, previously unknown to students, such as the parallel mastering of two specialties. In our opinion, such a system of vocational education, through the competent and purposeful application of leading modern pedagogical technologies, can significantly replenish both the theoretical and practical base of modern pedagogical science.

\section{References}

1. G.S. Altshuller, Find an idea. Introduction to TIPS - Theory of Inventive Problem Solving, p. 202 (Alpina Business Books, 2007)

2. V.P Bespalko, The components of pedagogical technology, p. 154 (Moscow: Education, 1989)

3. I.P. Volkov, We teach creativity, p. 142 (Moscow: Education, 1986) 
4. A.A. Getmanskaya, The modular approach in the formation of core competencies in students, Internet magazine "Eidos", electronic resource http://www.eidos/ru/journal/2005/1910-24.htm (2005)

5. T.E. Zlygosteva, Rating technology of modular training, electronic resource https://ito.su/2003/VI/VI-0-2394.html (2003)

6. V.A. Kavera, Modern pedagogical technologies in the system of additional education of children, Proceedings of the Saint Petersburg state University of culture and arts, 195, 159-170 (2013)

7. M.V. Klarin, Pedagogical technology in the educational process, p. 234 (Moscow: Knowledge, 1989)

8. V. Knyaginin, N. Trunova, Competence approach and post-industrial labor market, Center for strategic development "North-West", 4, 32 (2005)

9. I.A. Kolesnikova, Fundamentals of technological culture of a teacher: a scientific and methodological guide for the system of professional development of educational workers, p. 288 (Publishing house "bustard", Saint-Petersburg, 2003)

10. I.Ya. Lerner, Pain points of the learning process, Soviet pedagogy, 5, 24-29 (1991)

11. T.M. Mikhailenko, Game technologies as a type of pedagogical technologies, Pedagogy: traditions and innovations, 1, 140-146 (2011)

12. M.Yu. Oleshkov, Pedagogical technology: the problem of classification and implementation, Professional and pedagogical technologies in the theory and practice of training: Collection of scientific papers, 5-19 (2005)

13. B.A. Sazonov, System of credit units: features of the organization and calendar planning of the educational process, Research center of quality problems of training of specialists, p. 104 (Moscow: Research. center for training quality problems, specialists, 2005)

14. Yu.G. Tatur, Competence in the structure of the quality model of training specialists, Higher education today, 3, 21-26 (2004)

15. T.B. Feiling, Modern educational technologies in additional professional education, Izvestiya RSPU named after A.I. Herzen, 44, $485-489$ (2007)

16. A.Yu. Chernov, Qualitative approach in psychological research, p. 339 (Volgograd: Volga publishing house, 2008)

17. M.A. Choshanov, Flexible technology of problem-modular training, p. 157 (Moscow: Public education, 1996)

18. V.D. Shadrikov, Development of junior schoolchildren in various educational systems, p. 232 (Moscow: Logos, 2011)

19. I.S. Yakimanskaya, The foundations of personality-oriented education, p. 220 (Moscow: BINOM. Knowledge lab, 2013) 